\title{
Degradation Problem Identified
}

National Cancer Institute

\section{Source}

National Cancer Institute. Degradation Problem Identified. NCI Thesaurus. Code C92041.

Problems that occur when the device becomes worn, weakened, corroded, or broken down due to processes such as aging, permeation, and corrosion. 